\title{
Complex Decapod Burrows and Ecological Relationships in Modern and Pleistocene Intertidal Carbonate Environments, San Salvador Island, Bahamas
}

H. Allen Curran

Smith College, acurran@smith.edu

Anthony J. Martin

Emory University

Follow this and additional works at: https://scholarworks.smith.edu/geo_facpubs

Part of the Geology Commons

\section{Recommended Citation}

Curran, H. Allen and Martin, Anthony J., "Complex Decapod Burrows and Ecological Relationships in Modern and Pleistocene Intertidal Carbonate Environments, San Salvador Island, Bahamas" (2003). Geosciences: Faculty Publications, Smith College, Northampton, MA.

https://scholarworks.smith.edu/geo_facpubs/39 


\title{
Complex decapod burrows and ecological relationships in modern and Pleistocene intertidal carbonate environments, San Salvador Island, Bahamas
}

\author{
H. Allen Curran ${ }^{\mathrm{a}, *}$, Anthony J. Martin ${ }^{\mathrm{b}}$ \\ a Department of Geology, Smith College, Northampton, MA 01063, USA \\ b Department of Environmental Studies, Emory University, Atlanta, GA 30322, USA
}

Received 6 May 2002; accepted 6 December 2002

\begin{abstract}
Burrowing by thalassinidean shrimp in modern tropical, shallow-subtidal to intertidal carbonate environments is widespread and a powerful agent of bioturbation, particularly within sandy substrates. Deep and intense burrowing by callianassids commonly occurs along the intertidal margins of hypersaline lagoons throughout the Bahamas, such as Pigeon Creek on San Salvador Island, where the sediments of extensive sand flats are thoroughly bioturbated by Glypturus acanthochirus. In addition to dominating the deep-tier infauna, G. acanthochirus is a true ecosystem engineer, and its prodigious burrowing activity results in a highly mounded topography. On sand flats, individual sediment cones commonly coalesce with time to form large composite mounds with surfaces stabilized by the development of microbial mats. This unique, biogenetically produced topography sets the stage for colonization by shallow-tier burrowers, particularly the upogebiid shrimp Upogebia vasquezi and several species of fiddler crabs. Burrow systems of $U$. vasquezi are distinctive and complex. They typically consist of a pair of U-shaped burrows in close proximity or criss-crossing, with knobs or short tunnels at their bases. The entire U-burrow pair is lined by a thick, externally pelleted wall. Inside burrow diameters range from 0.2 to $1 \mathrm{~cm}$, and burrow depths are $10-15 \mathrm{~cm}$, in contrast to the much deeper callianassid burrows. These complex upogebiid burrows also occur as trace fossils in late Pleistocene lagoon-margin facies of the Grotto Beach Formation on San Salvador. Initially reported as fragmentary burrow fills, whole burrow systems virtually identical to the modern upogebiid burrows recently have been found at several localities. These fossil burrows are most abundant in beds lying immediately below a terra rossa paleosol that marks the late Pleistocene-Holocene stratigraphic boundary, and the beds likely were deposited with sea-level stillstand and regression associated with the onset of Wisconsinan glaciation. With their high potential for preservation, these complex upogebiid trace fossils may prove useful as both paleoenvironmental and sea-level position indicators in the study of Quaternary carbonate sequences throughout the Bahamas and other geologically similar regions.
\end{abstract}

(C) 2002 Elsevier Science B.V. All rights reserved.

Keywords: complex trace fossils; decapod burrows; callianassid and upogebiid shrimp; fiddler crabs; sea-level indicators; Quaternary; Bahamas

\footnotetext{
* Corresponding author.

E-mail addresses: acurran@email.smith.edu (H.A. Curran), geoam@learnlink.emory.edu (A.J. Martin).
} 


\section{Introduction}

Sedimentary geologists and marine biologists visiting the Bahamas and other similar areas in the wider Caribbean and observing for the first time tropical, intertidal and shallow-marine carbonate sedimentary environments soon will notice the distinctive sediment cones, or 'volcanoes', and adjacent funnel-shaped burrow openings that commonly are numerous and large. This distinctive topography is widespread on open to lightly seagrass-covered, sandy bottoms of shelf, lagoon, and lagoon-margin environments found throughout the region. The sediment cones and funnels are formed by the burrowing activity of callianassid shrimp, fossorial thalassinidean crustaceans that spend their entire lives in extensive, deep, and complex burrow systems. The occurrence of callianassids spans the globe, and, particularly in tropical, shallow-marine carbonate settings, bioturbation by these callianassid ecosystem engineers (in the sense of Jones et al., 1994) commonly is the dominant process of modification of original sedimentary fabrics of deposition (Tudhope and Scoffin, 1984; Tedesco and Wanless, 1991; Curran, 1994).

Pigeon Creek is a large, tidally influenced, slightly hypersaline lagoon located in the southeastern corner of San Salvador Island (Fig. 1). The intertidal margins of the lagoon support a fringe of mangroves that commonly give way lagoonward to extensive carbonate sand flats. These sand flats have a distinctive topography of mounds and craters formed by the callianassid shrimp Glypturus acanthochirus. Secondary burrowing by upogebiid shrimp and fiddler crabs occurs on the large mounds.

The primary purpose of this paper is to describe and analyze the complex upogebiid burrows and the relationships between burrowers and burrow forms that occur on the mounded sand flats of Pigeon Creek. This is a prime example of habitat control and benthic ecosystem restructuring by infaunal, trace-producing organisms, as discussed by Miller (1998, 2002). Emphasis is placed on the characteristics of the various burrow types found within the mounds, particularly the distinctive burrows of Upogebia vasquezi. The manifestation of sand flats in the tropical carbonates rock record and the geologic significance of fossil $U$. vasquezi burrows, particularly with respect to recognition of past sea-level position, are important points that also will be considered.

The ichnology of the Pigeon Creek sand flats was described initially by Curran (1994, 1997) and Curran and Williams (1997). It was recognized early on that the Upogebia vasquezi burrows have high potential for fossilization. The discovery of fossil $U$. vasquezi burrow fills was reported by Noble et al. (1995), and Martin (1999) described more extensive occurrences of $U$. vasquezi burrows in late Pleistocene strata on San Salvador. More recently, new specimens have been found, and the utility of this trace fossil for geological interpretation has expanded.

Specimens of all decapod taxa cited in this paper were identified by the late Austin B. Williams of the National Marine Fisheries Service, Systematics Laboratory, U.S. National Museum of Natural History. Voucher specimens are catalogued in the collections of the National Museum of Natural History (Smithsonian Institution), Washington, DC.

\section{The geological setting: modern and ancient}

\subsection{The modern intertidal site - Pigeon Creek, San Salvador Island}

The study area for the modern burrows is a large, lobate, intertidal sand flat located in the south arm of Pigeon Creek (Fig. 1). This sand flat borders the northwest side of this tidal lagoon system. The site is inaccessible from the land, but can be reached easily by boat from the dock area located at the mouth of the south arm of Pigeon Creek (distance of about $500 \mathrm{~m}$ ). Normal tidal range for this part of the lagoon averages about $0.6 \mathrm{~m}$, and the sand flat is completely flooded at high tide. With fair weather conditions, the sandflat surface is emergent about $2 \mathrm{~h}$ before a predicted low tide. Salinity varies significantly within the larger Pigeon Creek lagoon system (Mitchell, 1987), but the flats normally are flooded by water 


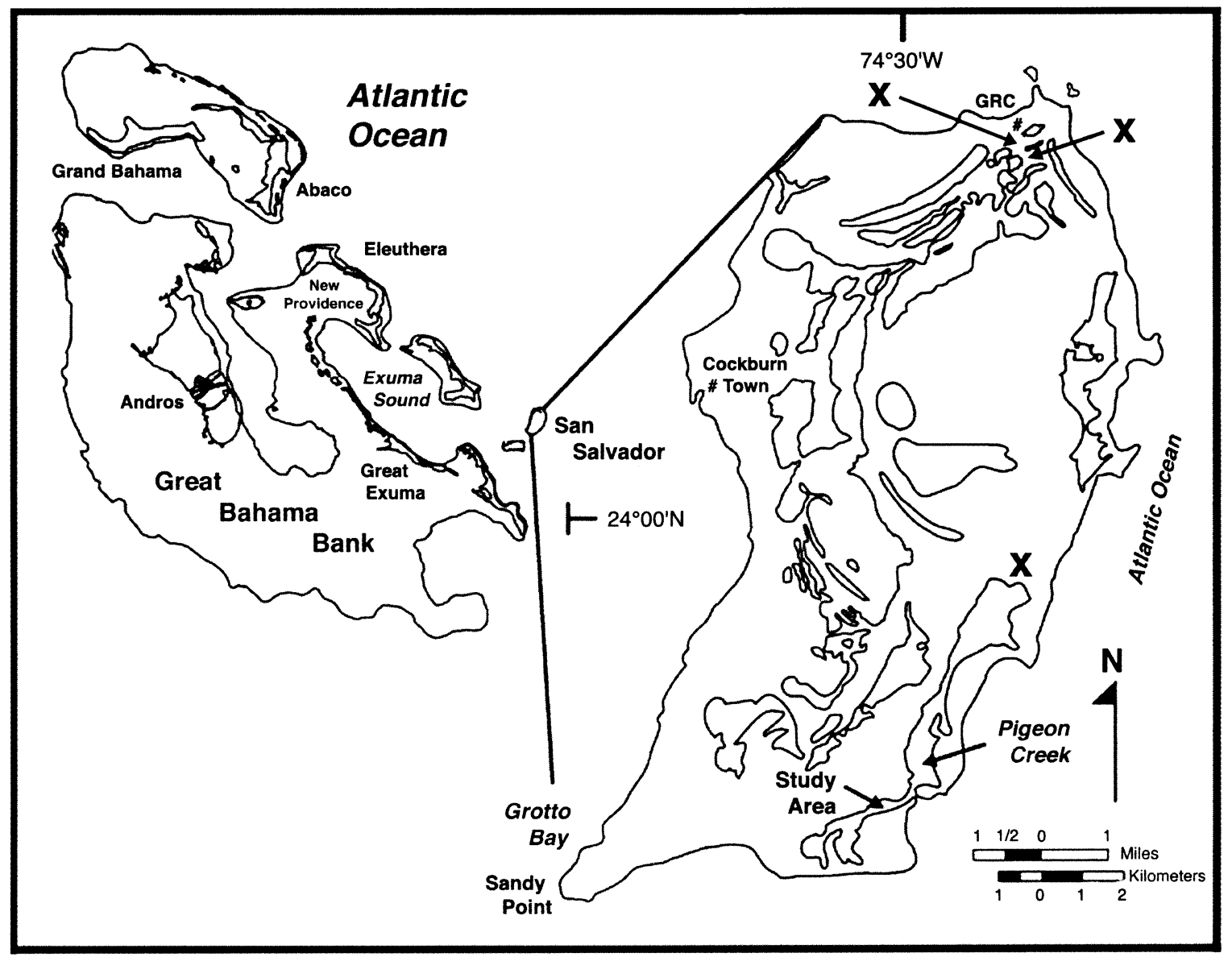

Fig. 1. Location of San Salvador Island within the Bahama Archipelago. Inset map shows location of the modern sand-flat study site on the south arm of Pigeon Creek. The fossil localities discussed herein are indicated by Xs; upper left X marks the Osprey Lake locality and upper right X marks the Moonrock Pond locality. Lower X near Pigeon Creek indicates the North Pigeon Creek Quarry locality. GRC denotes the location of the Gerace Research Center on the north coast of San Salvador.

that is at, or just slightly above, the offshore salinity (typically $36-37 \%$ ).

The main channel of the south arm of Pigeon Creek is underlain and confined by late Pleistocene limestone. Adjacent to the study area, the channel is deep and has a swiftly moving, reversing tidal current. Farther to the south, the lagoon opens up considerably and shallows. Here the lagoon is bounded to the east by Holocene beach and dunal sediments of a strand plain as described by Carney et al. (1993).

Extensive sand flats also border much of the north arm of Pigeon Creek, and they exhibit essentially identical sedimentologic and ichnologic characteristics to those in the study area. Parts of these flats can be reached easily at low tide from the road near the localities marked Old Place Settlement and Pigeon Cay on the topographic map of San Salvador.

Characteristics of the sediments, thickness of the Holocene sediment package, topography, and ecological zonation of the Pigeon Creek sand-flat study area were reported in some detail by Curran and Williams (1997). A brief summary is presented here. Pigeon Creek sediments were described by Mitchell (1987) and by Cummins et al. (1995). Mitchell (1987) defined 12 lithofacies within the lagoon complex, based on differences 


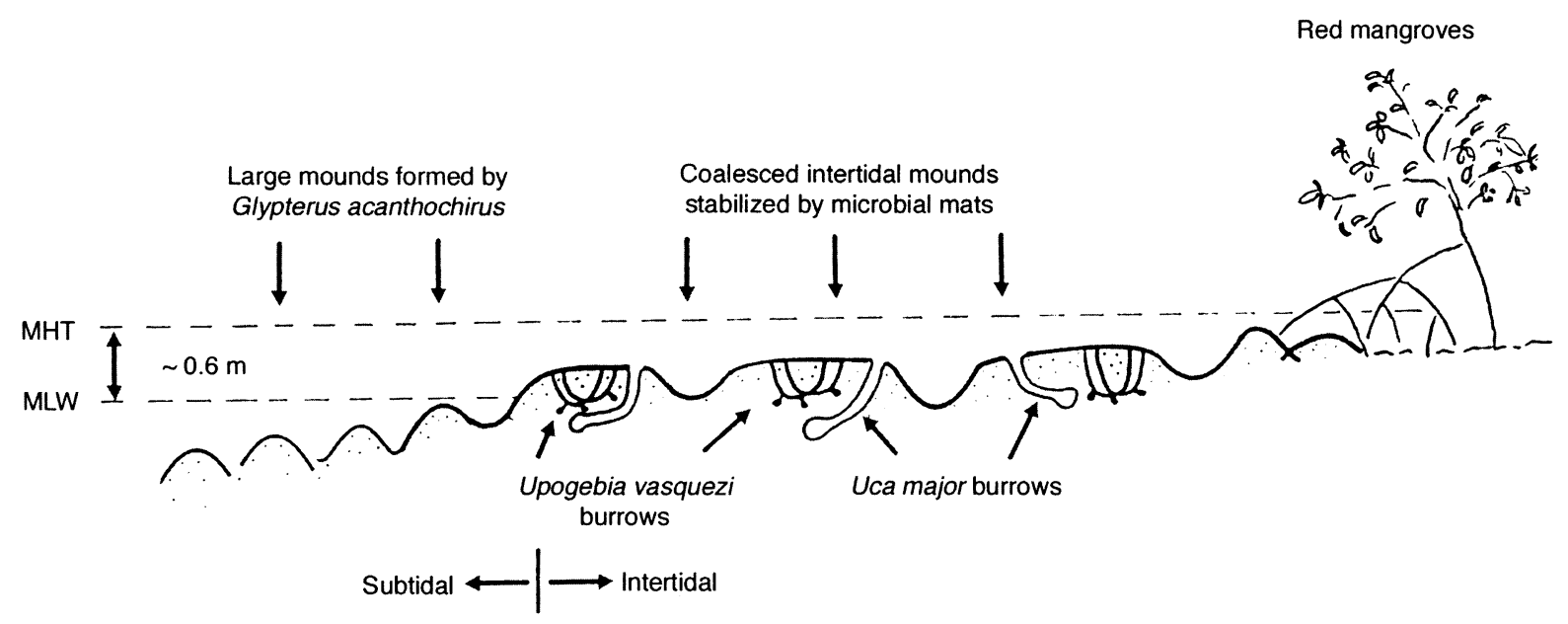

Fig. 2. Generalized profile across the Pigeon Creek sand flat showing the intertidal zones and occurrence of the dominant shallow-tier burrows in the coalesced mounds generated by the deep-burrowing callianassid Glypturus acanthochirus. In the study area, the sand flat is exposed at low tide for a distance of about $190 \mathrm{~m}$ from the edge of the red mangroves (proximal). The distal $40-50 \mathrm{~m}$ of the flat comprise the scoured zone discussed in the text.

in mean grain size and dominant grain morphotypes. The sand-flat study area lies in Mitchell's Halimeda sand lithofacies. Using essentially the same criteria, Cummins et al. (1995) recognized four lithofacies in the south arm of Pigeon Creek, with the study area within their Halimeda-rich 'packstone' facies. Our sediment samples from the sand flat were composed dominantly of very fine to fine carbonate sand, with the medium sand and larger grain components consisting of peloids and Halimeda, foraminifera, and mollusk fragments. The dominant recognizable skeletal grains were fragments of Halimeda, large foraminifera, and cerithiid gastropods. The mud component ranged from $<10 \%$ to just over $20 \%$, with an average of about $10-12 \%$. This sediment is highly bioturbated. Can cores taken from the flat showed no primary sedimentary structures whatsoever; the sediment has a homogeneous to mottled appearance resulting from the intense burrowing activity within the sand flat.

Thickness of the Holocene sediment package overlying late Pleistocene bedrock was measured at $10-\mathrm{m}$ intervals across the sand-flat study area using an expandable steel rod sediment probe. The profile revealed that sediment reaches a maximum thickness of nearly $4 \mathrm{~m}$ on the outer part of the flat (Curran and Williams, 1997, fig. 3), more than $100 \mathrm{~m}$ from the edge of the mangroves bordering the sand flat. Presumably all of this carbonate sediment was generated and deposited during the past 3000 years with the flooding of the inner San Salvador shelf during the Holocene marine transgression (Boardman et al., 1989; Carney et al., 1993).

The generalized topography and ecological zonation of the Pigeon Creek sand flat is shown in Fig. 2; a more detailed profile was given by Curran and Williams (1997, fig. 3). The highly mounded topography of the sand flat, as shown in Fig. 3, results principally from the prodigious burrowing activity of the callianassid shrimp Glypturus acanthochirus. On a daily basis, these shrimp expel sediment from their burrows, forming sediment cones, or 'volcanoes', that can achieve heights of greater than $30 \mathrm{~cm}$. Sediment enters the burrow systems from the sand-flat surface through adjacent funnel-shaped burrow openings. In several experiments, dyed sediment was placed into what appeared to be active burrow funnels, and in all cases the dyed sediment appeared on the surfaces of adjacent cones by the next day. With time and continued burrowing activity, closely spaced sediment cones tend to coalesce, forming large mounds that become flattened by tidal currents. Such mounds commonly grow 


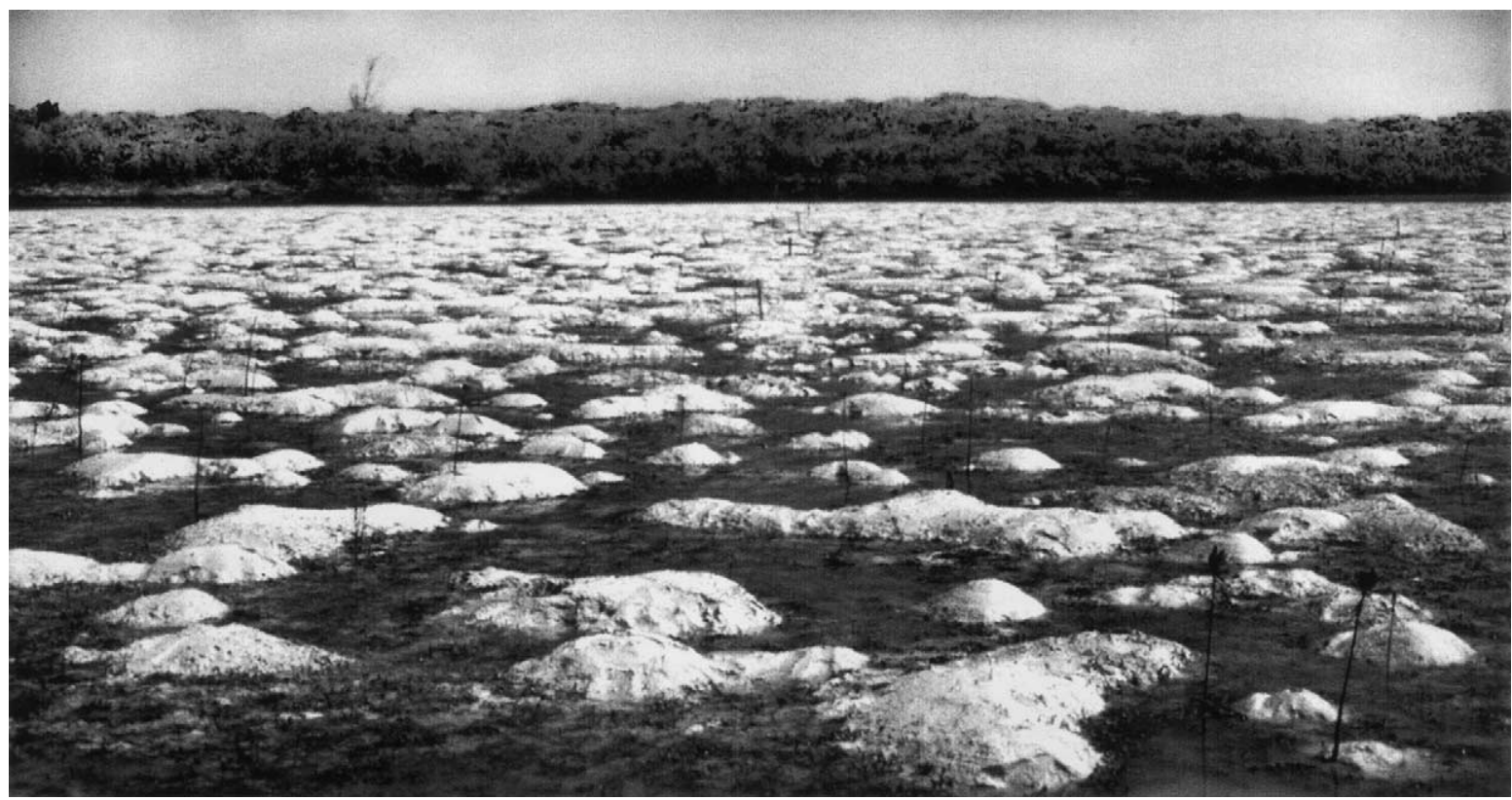

Fig. 3. View at low tide of the characteristic mound and crater topography of the sand flat bordering the south arm of Pigeon Creek; looking east, straight across the study area toward the main channel of the lagoon.

to greater than $1 \mathrm{~m}$ in diameter. Several distinctive aspects of the carbonate sand-flat environment are that these mounds actually accrete in this setting, are long-lived, and are not destroyed by storm waves and currents, as would be the case in shallow subtidal settings. Indeed, the surfaces of the large mounds are stabilized by the development of Schizothrix-dominated microbial mats that tend to armor the surfaces of the mounds. The result is the distinctive and surprisingly stable topography of mounds and craters as seen in Fig. 3.

In the study area, the distal part of the sand flat, beyond about $140 \mathrm{~m}$ from the proximal red mangrove fringe, is noticeably flatter and has a distinctly scoured appearance with fewer fresh sediment cones. This scoured character of the distal part of the sand flat results from its close proximity to the main channel of Pigeon Creek; tidal currents and small waves affect this area daily. There continues to be a significant amount of burrowing in this area, and the flat remains covered by extensive microbial matting. In fact, poorly lithified chips of mat sediment are common here. The burrow density distribution data of Table 1 show that the shallow-tier burrows, as discussed in Section 2.2, are less abundant on this part of the flat.

A general zonation for the occurrence of the most common species of flora and fauna found

\section{Table 1}

Comparison of the density of occurrence of the different types of shallow-tier burrows on surfaces of coalesced mounds in the well-mounded section of the Pigeon Creek sand-flat study area versus the scoured, distal section of the sand flat beyond $140 \mathrm{~m}$ (modified from Curran and Williams, 1997)

\begin{tabular}{|c|c|c|c|c|c|}
\hline \multicolumn{3}{|l|}{ Well-mounded area } & \multicolumn{3}{|l|}{ Scoured area } \\
\hline Upogebia vasquezi & Uca major & Small Uca spp. & Upogebia vasquezi & Uca major & Small $U c a$ spp \\
\hline $\begin{array}{l}4.8 \\
\text { burrows per } \mathrm{m}^{2} \\
n=24 \mathrm{~m}^{2} \text { quadrats }\end{array}$ & 0.8 & 4.5 & $\begin{array}{l}3.3 \\
\text { burrows per } \mathrm{m}^{2} \\
n=24 \mathrm{~m}^{2} \text { quadrats }\end{array}$ & 0.7 & 3.6 \\
\hline
\end{tabular}


on the sand flat was given by Curran and Williams (1997, fig. 3). The flat is sparsely covered by the seagrasses Thalassia testudinum and Halodule wrightii, except for the barren, scoured area. Presumably owing to desiccation, these seagrasses are excluded from the mound surfaces and are confined to the craters and small channel areas, which are ponded at low tide. Several species of calcareous green algae also grow in these ponded areas. In addition to the burrowing decapod species, small cerithiid gastropods are abundant grazers on the coalesced mound surfaces, and some shallow-burrowing bivalves are present as well.

\subsection{Occurrence and localities of the late Pleistocene upogebiid trace fossils}

The upogebiid trace fossils are preserved in muddy calcarenites (packstones) of the Grotto Beach Formation (late Pleistocene), following the stratigraphic nomenclature of Carew and Mylroie (1995). The most abundant occurrences of the fossil burrows are immediately below the terra rossa paleosol that marks the late Pleistocene-Holocene stratigraphic boundary on San Salvador, along the Gerace Research Center (formerly the Bahamian Field Station) Nature Trail in the northeastern part of San Salvador (Fig. 1). With reference to the map in the Nature Trail Field Guide of Godfrey et al. (1994), fossil burrow fills have been found in some abundance along the northern and eastern edge of Moonrock Pond and along the trail between Oyster Pond and Osprey Lake. Another, less prolific, locality for the fossil burrows is the North Pigeon Creek Quarry (Fig. 1), near the shoreline of the north arm of Pigeon Creek. Further details for all of these localities are given in Martin (1999).

\section{The modern decapod burrowers, burrow characteristics, and interrelationships}

\subsection{The callianassid Glypturus acanthochirus Stimpson, 1866 and its burrows}

The deep-tier, sediment cone- and mound-forming burrower of the Pigeon Creek sand flat is the large callianassid shrimp Glypturus acanthochirus. Fig. 4 illustrates the distinctive part of a burrow cast and a specimen of G. acanthochirus. This callianassid is difficult to capture, but success was achieved using a yabby pump. All specimens obtained from the sand flat proper were identified as G. acanthochirus. However, it is likely that more than one species of callianassid resides along the distal edge of the flat and in the Pigeon Creek tidal channel. In addition to $G$. acanthochirus, specimens of Neocallichirus rathbunae and an unidentified species were recovered from this area, indicating that the zonation of callianassid species within the whole of Pigeon Creek may be quite complex.

The presence of sediment cones is not sufficient evidence for identification of any given callianassid species. For example, in Grahams Harbour, at the north end of San Salvador, large sediment cones are common, but specimens of Glypturus acanthochirus have not been recovered. Here the large sediment cones are made by different callianassid species (Curran, 1997). Given that no firm identification of callianassids is possible without capture of live specimens and that such capture is difficult, there is very little firm information about the distribution patterns of callianassids in tropical, shallow-marine environments. Complex distribution patterns also were reported by Dworschak and Ott (1993) for tropical callianassids in the mangrove-channel and back-reef environments of Belize.

Glypturus acanthochirus is widespread in the shallow marine carbonate environments of the Bahamas and Caribbean, and it is thought to be primarily a deposit feeder (Griffis and Suchanek, 1991; Dworschak and Ott, 1993). Seagrass found in chambers deep within its extensive and complex burrow system has led to speculation that the shrimps also do some 'gardening' and graze on the microbe-rich surfaces of the decaying seagrass blades (Bromley, 1996). Regardless, it is clear that G. acanthochirus shrimp process or otherwise manipulate considerable amounts of sediment. Coarser material appears to be moved into the deep tunnels and thus represents a significant activity of the shrimps (Tedesco and Wanless, 1991; Dworschak and Ott, 1993). 
Using resin casts, Dworschak and Ott (1993) described in some detail the complex burrow morphology of Glypturus acanthochirus from Belize. Shafts extend down from funnel-shaped (incurrent) openings. Typically, at $30-50 \mathrm{~cm}$ beneath the surface, the central shaft begins to spiral, and tunnels radiate outward. This pattern continues downward for the length of the burrow systems, which commonly go to depths greater than $1 \mathrm{~m}$. Indeed, Dworschak and Ott (1993) traced one burrow to a depth of $1.6 \mathrm{~m}$. Resin casts virtually identical in form to those of Dworschak and Ott (1993) have been made by the senior author from burrows on the Pigeon Creek flats. Casts of burrows generically attributed to Callianassa were figured by Shinn (1968) from Florida and the Bahamas and by Tedesco and Wanless (1991, and Fig. 4A herein) from Florida and the Caicos Platform, British West Indies. Given the identical morphologic form to the Pigeon Creek burrows made by $G$. acanthochirus, it is most likely that these figured generic Callianassa burrows were constructed by G. acanthochirus. Dworschak and Ott (1993, p. 287) share this conclusion. Excellent diagrams of the complex $G$. acanthochirus burrow form are given in Shinn (1968) and Bromley (1996).

Shinn (1968) and Dworschak and Ott (1993) reported that callianassid burrow cones do not maintain a free connection to the underlying burrow system, although the excurrent holes at the tops of cones commonly are open and surrounded by fecal pellets. This conforms to our observations; presumably the excurrent openings become passively blocked with sediment that is easily expelled by the outflow current generated by the shrimps. The burrows are lined, with a smooth interior surface and pelleted exterior. Such burrows should be readily preservable as fossils, and would be assigned to the ichnogenus Ophiomorpha. Although Ophiomorpha is widespread in late Pleistocene subtidal calcarenites of the Bahamas (Curran and White, 1991; Curran, 1994), the spiral form of the Glypturus acanthochirus burrow has not yet been reported as a fossil.

Shinn (1968), Tedesco and Wanless (1991), and Dworschak and Ott (1993) all found that burrow chambers deep within the burrow system of Glyp-
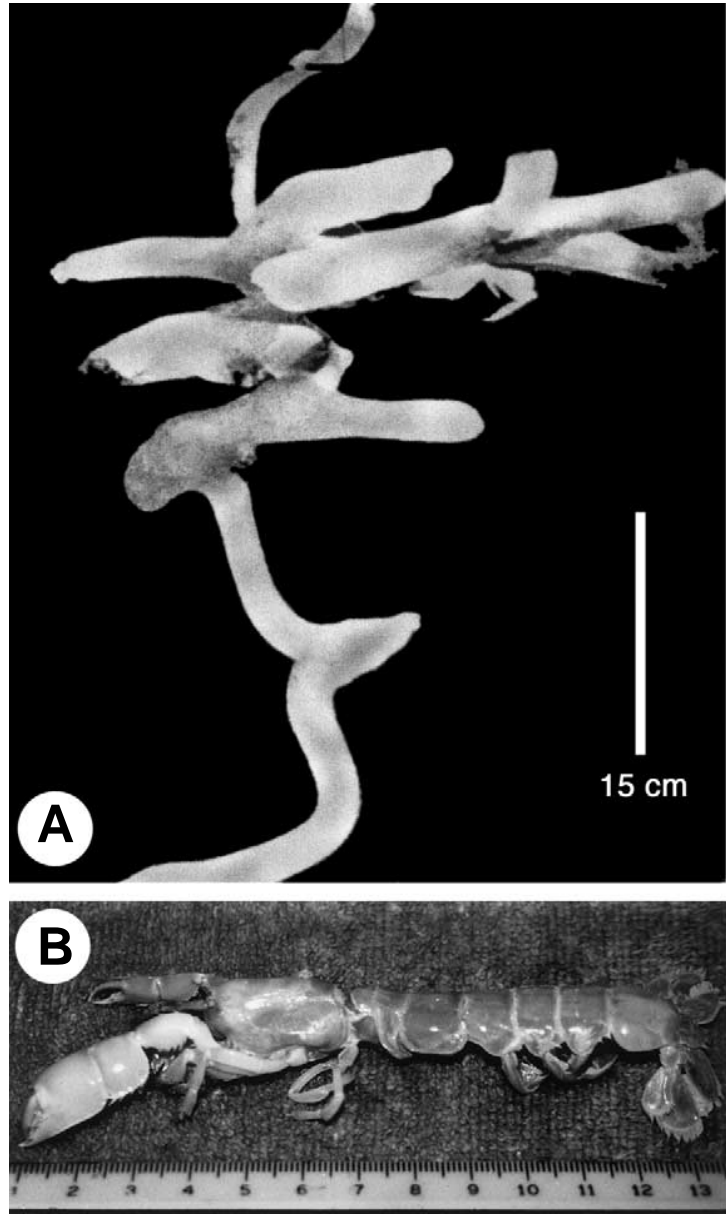

Fig. 4. (A) Resin cast of part of a presumed Glypturus acanthochirus burrow from the Turks and Caicos (photo courtesy of Lenore Tedesco; see Tedesco and Wanless, 1991). This burrow form is virtually identical to those made by $G$. acanthochirus in the Pigeon Creek study area. (B) Mature specimen of the callianassid shrimp G. acanthochirus, collected from the Pigeon Creek sand flat.

turus acanthochirus commonly serve as repositories for shell and rubble material that enters the burrow system through the funnel openings. Tedesco and Wanless (1991) demonstrated that this infilling process is highly important in changing the original fabric of the underlying sedimentary deposits and results in a distinctive ichnofabric. Deep cores have not been taken across the Pigeon Creek sand flat, but it seems likely that at least some coarse-sediment trapping is taking place at depth within the $G$. acanthochirus burrow systems 
present there. Abundant cerithiid gastropod shells and other mollusk shells and shell fragments are available on the sand flat for transport into burrow funnels, although the amount of shelly debris present on the Pigeon Creek surface appears to be less than is the case for the areas studied by Tedesco and Wanless (1991).

\subsection{The upogebiid Upogebia vasquezi Ngoc-Ho, 1989 and its burrows}

The coalesced mounds initiated by the burrowing activity of the callianassid Glypturus acanthochirus and stabilized by the development of microbial mats present an ideal habitat on the Pigeon Creek sand flat for colonization by shallow-tier burrowers that require a stable, relatively firm substrate. These stabilized softground surfaces typically bear numerous burrow openings that are flush with the surface, in contrast to the funneled callianassid burrow openings located mostly in the ponded areas between mounds. These are the burrow openings of upogebiid and ocypodid (in this case fiddler crabs, genus $U c a$ ) decapods that form permanent and semi-perma- nent dwelling structures across the sand flat. Their generalized pattern of occurrence is shown in Fig. 3, and abundance data are presented in Table 1.

Numerous small burrow openings $(0.2-0.6 \mathrm{~cm})$ occur on the stabilized mound surfaces; some of these burrow openings appear to be paired, whereas others are obviously single. The paired openings, sometimes surrounded by recently expelled, small, cylindrical fecal pellets, are upogebiid burrows. In contrast, the single openings commonly are surrounded by larger sand pellets that are the feeding and excavation (larger still) pellets of small fiddler crabs, Uca spp., discussed in Section 3.3.

Closer investigation of the paired openings $(\sim 2-3 \mathrm{~cm}$ apart $)$ reveals that they typically have another pair close by, typically at distances of $2-5 \mathrm{~cm}$. Lines connecting the four openings normally make a roughly rectangular outline on the surface. By digging with a trowel, a hard burrow structure (semi-lithified burrow wall, as in Fig. 5) will be encountered just beneath the surface and typically will extend to depths of 10-15 $\mathrm{cm}$. These are the burrows of Upogebia vasquezi,

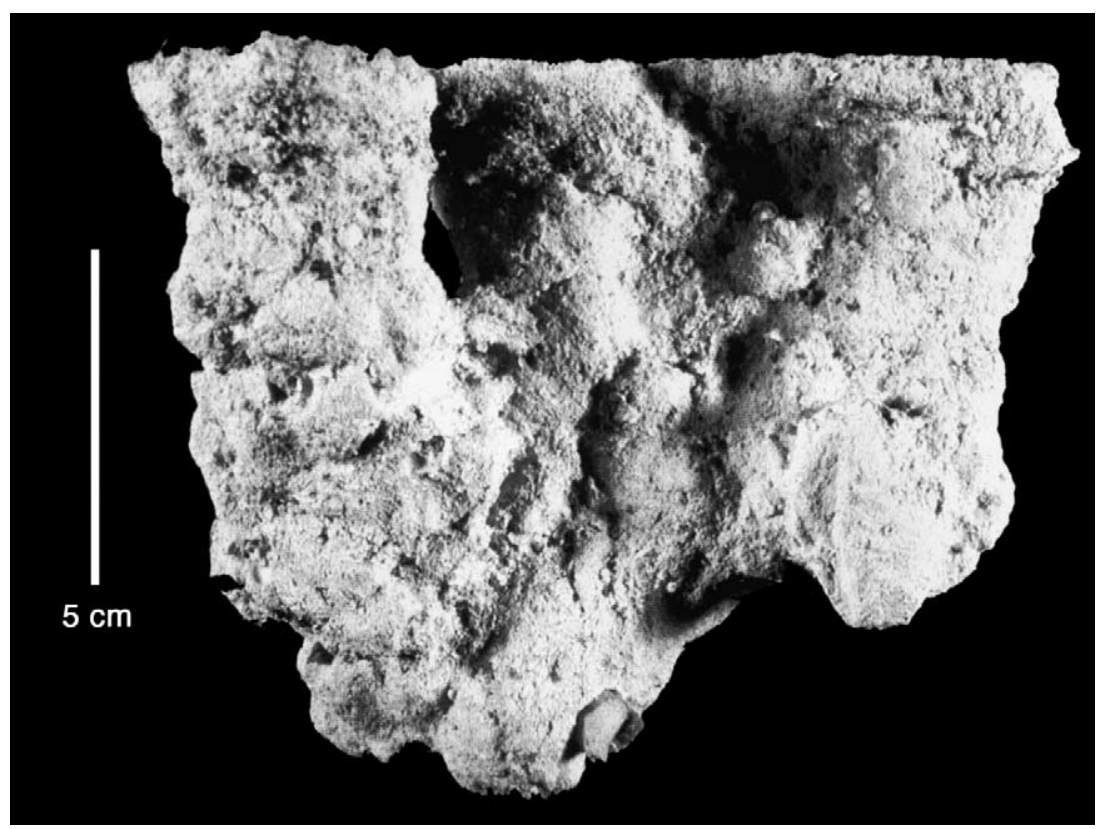

Fig. 5. Exterior view of a Upogebia vasquezi burrow extracted from a can core taken from a coalesced-mound surface in the Pigeon Creek study area. Note the knobby character of the outer burrow wall. 
and the burrow-maker can be easily captured by carefully breaking apart the burrow.

The entire Upogebia vasquezi burrow system can be collected by taking a can core with an open-ended one-gallon paint-thinner can, or equivalent. In the lab and with the core extracted, the burrow can be isolated by carefully washing the core with a gentle stream of water to remove the surrounding sediment. What is revealed is the very firm lining of a surprisingly large and ultimately complex burrow system. With care, the entire burrow system can be exposed (Fig. 5). If allowed to air-dry, the burrow wall will become quite hard.

Burrow casts made with polyester resin reveal that the Upogebia vasquezi burrow system consists of a pair of U-shaped burrows in very close proximity to each other and commonly criss-crossing (Fig. 6). The burrow openings for many, if not most, upogebiid species are constricted (Bromley, 1996, figs. 4.29-4.30; Astall et al., 1997; Coelho et al., 2000), and this is the case with $U$. vasquezi. Its burrow openings normally narrow to an inside diameter of $0.5 \mathrm{~cm}$ or less, but the burrows expand to a very consistent inside diameter of $0.6-1$ $\mathrm{cm}$ just below the openings. Constriction of the burrow openings is not apparent in the resin cast shown in Fig. 6 because funnel-shaped openings to the burrow must be cut from the sediment to facilitate entry of resin into the burrow when making a cast. Knob-like swellings or short tunnels of several centimeters in length and with the same inside diameter as the burrow shaft usually are present at the bases of the U-forms (Figs. 6 and 7).

This U-shaped burrow with knobs or short tunnels at the base of the U-form is common for upogebiid burrows, which typically have U- to Y-shaped burrows (Nickell and Atkinson, 1995), as illustrated by Bromley (1996) for several different species of Upogebia. Asgaard et al. (1997) described modern Upogebia mediterranea burrows from firmground deposits present along the coast of Rhodes, Greece. Their U-shaped morphology and general size are similar to that of the $U$. vasquezi burrows, but $U$. mediterranea burrows commonly are crowded and interconnect to produce intricate networks.

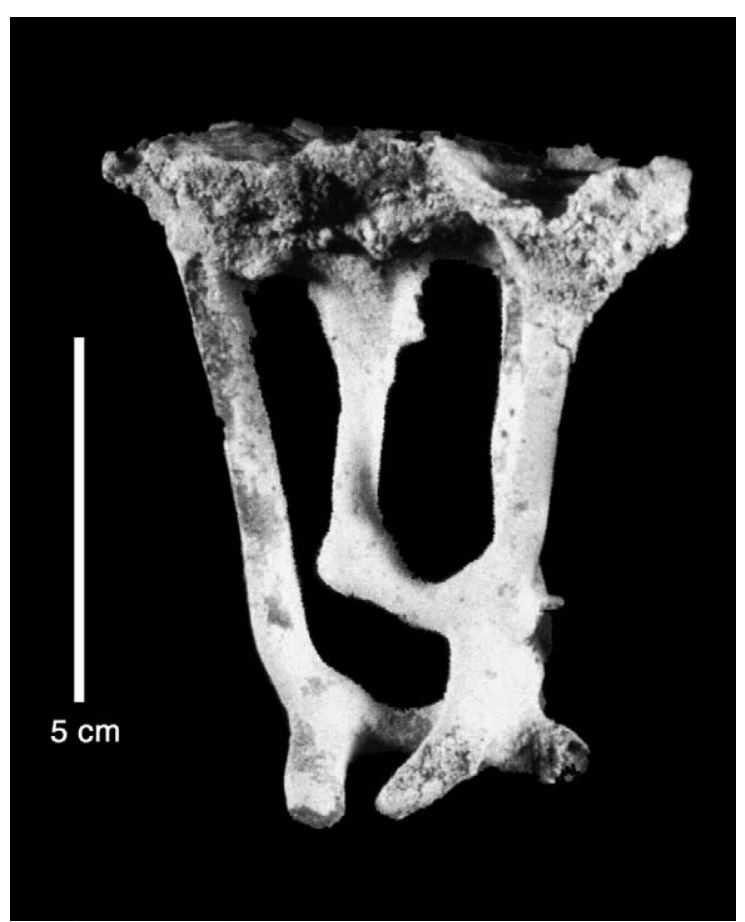

Fig. 6. Resin cast of a Upogebia vasquezi burrow from the Pigeon Creek study area showing distinctive double-U form and short tunnels at bases of the U-form.

More recently, upogebiid burrows have been described from shallow subtidal areas along the southeastern Brazilian coast by Coelho et al. (2000) and from a tidal flat in Tokyo Bay, central Japan, by Kinoshita (2002). The discussions in these papers suggest that a Y-shaped burrow form is the more common morphology for upogebiids, with the shaft of the Y (or I-part of Kinoshita) sometimes extending to considerable depth and very possibly facilitating deposit-feeding behavior. In the case of Upogebia major as described by Kinoshita (2002), the I-part (shaft) may extend to depths of more than $2.5 \mathrm{~m}$ beneath the tidal-flat surface.

The unique aspects of the Upogebia vasquezi burrow system are the seemingly obligatory double-U form, and the incredibly thick lining of agglutinated fine to very fine carbonate sand and mud that surrounds the entire double-U. Both U-forms are completely encased in the lining (Fig. 5). Single wall thickness typically is $1-1.5$ 


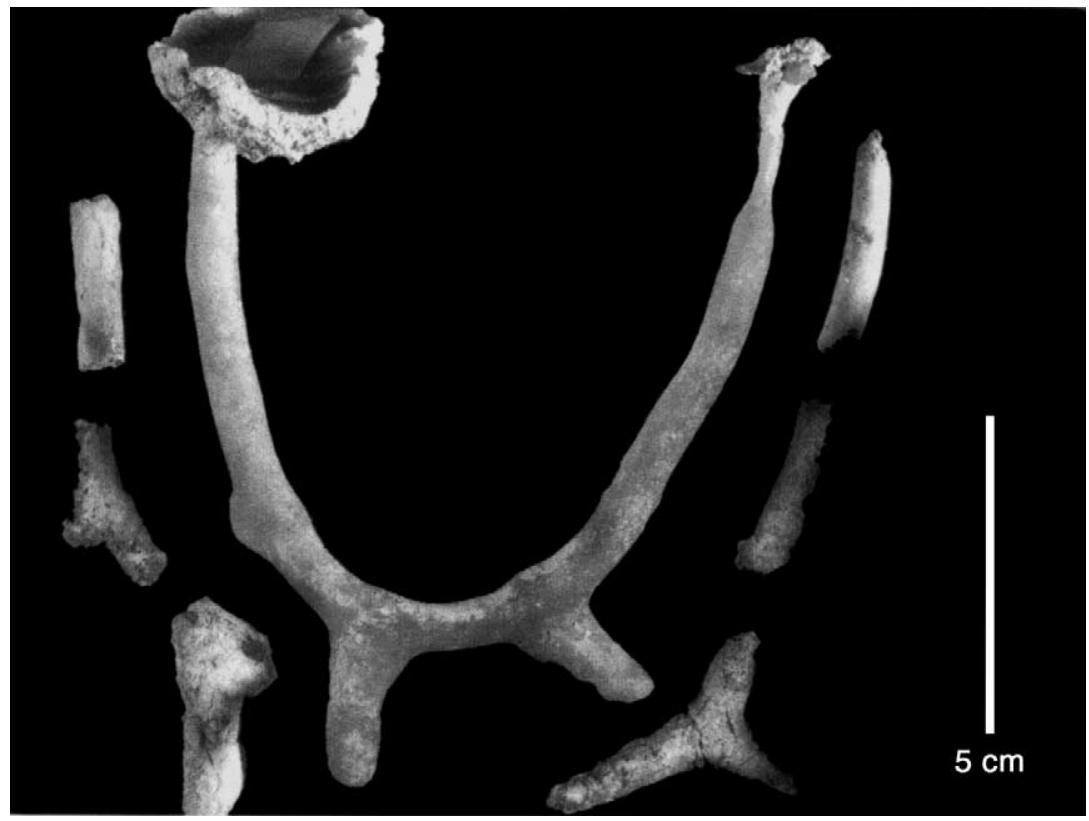

Fig. 7. Resin cast of a modern U-form of a Upogebia vasquezi burrow surrounded by lithified, morphologically similar, burrowfill segments collected from Grotto Beach Formation (late Pleistocene) exposures near Moonrock Pond on San Salvador, as described in the text.

$\mathrm{cm}$, and the wall surrounding the double-U commonly reaches a total thickness of $3-5 \mathrm{~cm}$. The inside surfaces of the burrow walls are polished smooth by the shrimps, but the outside surface of the entire burrow system is knobby and rough (Fig. 5), owing to the presence of very coarse pellets with diameters of about $1 \mathrm{~cm}$. These are real pellets; in fresh burrows individual pellets can be removed from the lining, and they are quite firm and made of the same fine to very fine sand and mud that characterizes the wall. Given that $U$. vasquezi shrimp typically are only $2.5-3$ $\mathrm{cm}$ in total length, it is remarkable that they can form such large pellets and construct such thick walls.

The sediment compaction/compression style of burrow formation with knobby exteriors is common to the burrowing upogebiids (Bromley, 1996). However, the large pellets and thick, wellagglutinated walls of the Upogebia vasquezi burrows appear to be unique to this species. Obviously these burrows have high potential for fossilization, and their occurrence as fossils and geologic implications will be discussed below.
Although only recognized and described as a new taxon in 1989, specimens of Upogebia vasque$z i$ have been reported from a wide geographic range throughout the Caribbean, Bahamas, and beyond (Williams, 1993). Unfortunately, the precise environmental setting for many of the occurrences remains uncertain. Most reports indicate an intertidal habitat, but more information on the environmental preference of this species is needed.

The burrows of some, if not most, upogebiid species typically contain only one individual per burrow (Coelho et al., 2000; Kinoshita, 2002). For Upogebia vasquezi, each U-form bears only one occupant, but the double-U structure of each burrow system contains two shrimps. Sex was determined for shrimps carefully extracted from 12 complete burrow systems sampled with can cores. In 11 of the 12 samples, the burrow system contained one male and one female shrimp. It is likely that a shrimp was lost in the washing process of the twelfth burrow system, where only one shrimp was recovered.

Virtually nothing is known about the functions 
of the complex burrows of Upogebia vasquezi beyond the information reported here. The burrow system clearly seems to represent an obligatory pairing of male and female shrimps, with a cooperative effort in construction of the burrow, although there are apparently no interconnections between the U-forms. The constricted nature of the burrow openings indicates that the shrimps do not commonly emerge from their burrows. Upogebia vasquezi is presumed to be a suspension feeder, as are most upogebiids (Kinoshita, 2002). The short tunnels at the bases of the U-forms were open and appeared clean in all Pigeon Creek samples investigated by the senior author, so these tunnels do not seem to function as repositories for seagrass or other debris, as is the case for several species discussed by Bromley (1996). Indeed, little if any sediment debris was found anywhere within these burrow systems. The interior surfaces of the burrow walls are highly polished, and the shrimp seem to be meticulous housekeepers.

In comparison with the burrows of other upogebiid species figured by Nickell and Atkinson (1995), Bromley (1996), Asgaard et al. (1997), Astall et al. (1997), Coelho et al. (2000), Kinoshita (2002) and in earlier reports, Upogebia vasquezi burrow systems are compact, highly modular entities. The presence of these burrow modules in the shallow tier adds real heterogeneity to the distribution of infauna on the Pigeon Creek sand flat.

With their burrows extending to great depth, Glypturus acanthochirus most likely is commonly subjected to and tolerant of hypoxic and reducing conditions. By contrast, with its compact, thickwalled and fairly shallow burrows (typically to 15 $\mathrm{cm}$ or less), Upogebia vasquezi is much more insulated from surrounding pore-water conditions. Thompson and Pritchard (1969) found that the deep-burrowing deposit feeder Callianassa californiensis (now Neotrypaea californiensis) was more tolerant to hypoxic and reducing conditions whereas the shallow-tier, suspension-feeding Upogebia pugettensis was well insulated in its burrows and had a higher metabolic rate. This comparison also may well apply for $G$. acanthochirus and $U$. vasquezi.

In addition to the above, there are other out- standing questions about Upogebia vasquezi and its burrows, including: (1) What is the mating strategy for individuals of this species? The burrow tubes have no obvious interconnection. (2) What is the burrow construction strategy of the apparently obligatory male-female pair? (3) What are the energetics for what would seem to be prodigious mucus production required to agglutinate the large pellets that form the thick burrow walls? (4) What is the function of the short tunnels at the bases of the U-forms; are they turnarounds, potential gardening areas, or other? Further research to answer these questions is required, but clearly the $U$. vasquezi burrows are complex. Their architecture is 'deliberate' as defined by Miller (1998), with their burrows restructuring habitat and producing spatial heterogeneity across the sand-flat environment.

\subsection{Fiddler crabs, Uca major (Herbst, 1782) and Uca spp., and their burrows}

Also present on the stabilized surfaces of the coalesced mounds are larger burrow openings up to $3-4 \mathrm{~cm}$ in diameter. These burrow openings can be distinguished from callianassid burrow openings in that they are flush with the substrate surface and do not have the characteristic funnel form, enter the substrate obliquely as opposed to near vertical, and commonly exhibit radiating scratch marks and feeding and excavation pellets typical of fiddler crabs. These obliquely oriented burrows are constructed by Uca major, a moderately large fiddler crab.

This species has a wide geographic range throughout the tropical western North Atlantic and Caribbean, but it is thought to be uncommon in most areas (Crane, 1975). Such is not the case on the Pigeon Creek sand flats, where a substantial Uca major population exists (Table 1). These dwelling burrows are unlined, have diameters of $2-5 \mathrm{~cm}$, and extend obliquely into the mound substrate following a gently meandering, somewhat irregular course for distances of up to 50 $\mathrm{cm}$ or more. Burrows end with a bulbous turnaround where the crab commonly is encountered (Fig. 8).

Fiddler crab burrows typically are ephemeral, 


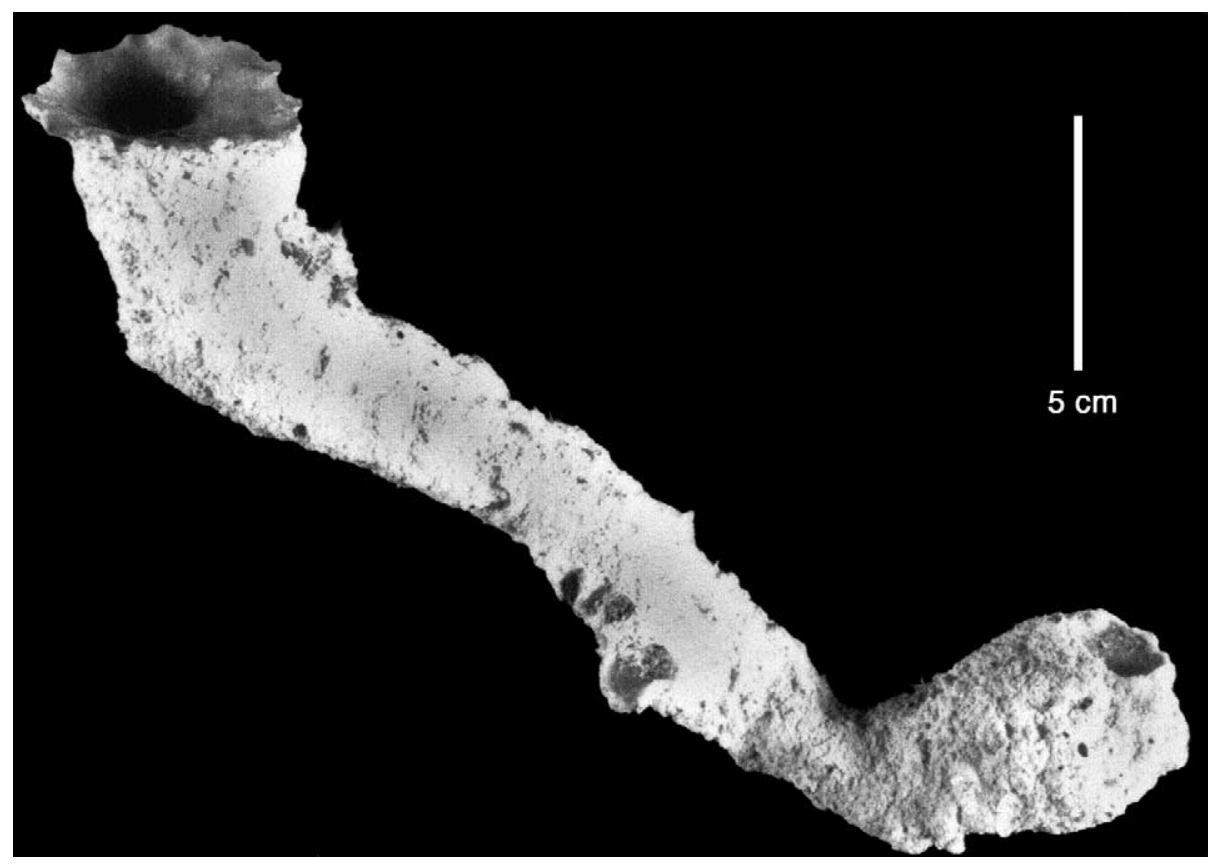

Fig. 8. Resin cast of a Uca major burrow from a coalesced mound surface in the Pigeon Creek study area.

but the burrows of adult Uca major fiddlers are lengthy, well-formed, and at least semi-permanent, although actual duration of individual burrow occupation has not been determined. These unlined dwelling burrows are not truly complex in form and have a much lower potential for preservation than the thick-lined burrows of Upogebia vasquezi. However, the Uca burrows do add significantly to the synecological complexity of the sand-flat mounds.

Shallow-tier fiddler crab burrows likely would be destroyed by the bioturbation of deeper-tier burrowers with a build-up of sediment during lateral accretion or marine transgression. However, the burrow walls are sufficiently coherent so that if filled and lithified, there would be a distinct boundary between the wall of the burrow and the infilling material. With this scenario, Uca major burrows could be preserved with sea-level regression. However, to date trace fossils of this form have not been reported from the rock record of the Bahamas.

As mentioned earlier and indicated in Table 1, there are numerous small fiddler crabs residing on the stabilized mound surfaces of the Pigeon Creek sand flats. These microbe-rich surfaces are productive grazing grounds for fiddlers. The small fiddlers are active in making simple, unlined burrows, with small openings, typically less than $1 \mathrm{~cm}$ in diameter, that extend nearly vertically to obliquely for relatively short distances into the substrate. The burrow forms are generally similar to those described for Uca pugilator, the sand fiddler common along the Atlantic coast of the USA (Allen and Curran, 1974).

Rigorous specific identification of these fiddlers has not been attempted. They may represent a mixture of Uca major juveniles and mature $U c a$ leptodactyla Rathbun, Uca rapax (Smith), and one or more unidentified fiddlers. Uca leptodacty$l a$ and $U$. rapax have been identified from areas along the margins of Pigeon Creek, but specimens have not been collected from the sand flat proper. The preservation potential for these small fiddler burrows is low, because they are unlined and would be easily destroyed by callianassid bioturbation, and such burrows have not been reported as trace fossils in Bahamian rocks. 


\subsection{Interrelationships between the burrowers and their burrows}

The deep-tier callianassid Glypturus acanthochirus qualifies as a true ecosystem engineer in the sense of Jones et al. (1994). Its prodigious burrowing activity moves significant quantities of sediment to the surfaces of tropical carbonate sand flats, such as found along the margins of Pigeon Creek. The close spacing of sediment cones formed by excurrent flows from within the burrow systems combined with the action of tidal currents and the sediment-stabilizing effects of the development of microbial mats results in a distinctive and unique topography of mounds and craters (Fig. 3). In essence, the habitat has been restructured by activity that Miller (1998, 2002) cited as characteristic of complex marine traceforming organisms.

With development of this Glypturus-generated intertidal topography, the stage is set for colonization by shallow-tier burrowers, in this case Upogebia vasquezi and the Uca species. The result is what Bromley (1996) termed 'neutral commensalism', in the sense that the presence of the shallowtier burrowers offers no real benefit to the callianassids. However, the slightly firmer substrates of the coalesced burrow mounds in this softground setting are critical and life-supporting for the shallow-tier burrowers. Upogebia vasquezi shrimps are not facile burrowers; rather they invest a great amount of energy toward construction of their elaborate, permanent, and modular domiciles.

To a lesser extent, the fiddler crabs follow the same pattern, although they are much more able burrowers. The fiddlers do, however, depend on the emergent and stabilized mound surfaces as their grazing pastures. It is interesting to note that the Pigeon Creek relationships are precisely the reverse of that figured by Bromley (1996, fig. 5.1) where the shallow-tier burrowers are dependent on the depressions created by the callianassid Neotrypaea californiensis. In the Pigeon Creek example, the dependence of the shallow-tier burrowers is on the intertidal burrow mound 'islands', not standing-water ponds as with $N$. californiensis and its shallow-tier dependents.

\section{The fossil upogebiid shrimp burrows}

The initial discovery of upogebiid burrow trace fossils in the Bahamas was in the form of lithified burrow fills from the lagoon-margin facies of the Grotto Beach Formation (late Pleistocene) on San Salvador, as reported by Noble et al. (1995). The form of these fossil burrow fills was so similar to resin casts of the modern Upogebia vasquezi burrows, particularly with respect to the tunnel juncture points along the burrow U-form (Fig. 7), that a upogebiid origin for the burrow fills seemed highly probable. However, it was not until the discovery of more morphologically varied trace fossil material by the junior author and his students that full confirmation of the match could be made. Essentially complete fossil $U$. vasquezi burrows as shown in Fig. 9 were found on groundsurface exposures of the Grotto Beach Formation in certain areas of the Gerace Research Center Nature Trail, along with the common occurrence of irregular-shaped segments of burrow walls (Fig. 10). The more complete trace fossil specimens exhibited at least some of the following characteristics: (1) vertically oriented U-shaped burrows that in some cases show criss-crossed double-U structure with short tunnels branching

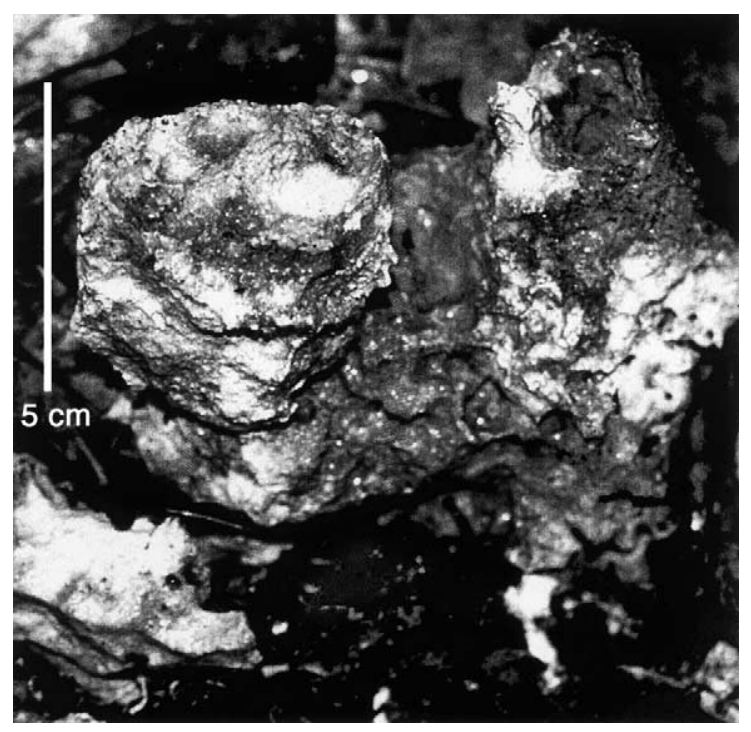

Fig. 9. In situ fossil Upogebia vasquezi burrow, Grotto Beach Formation, in exposures near Osprey Lake on San Salvador, as described in the text. 


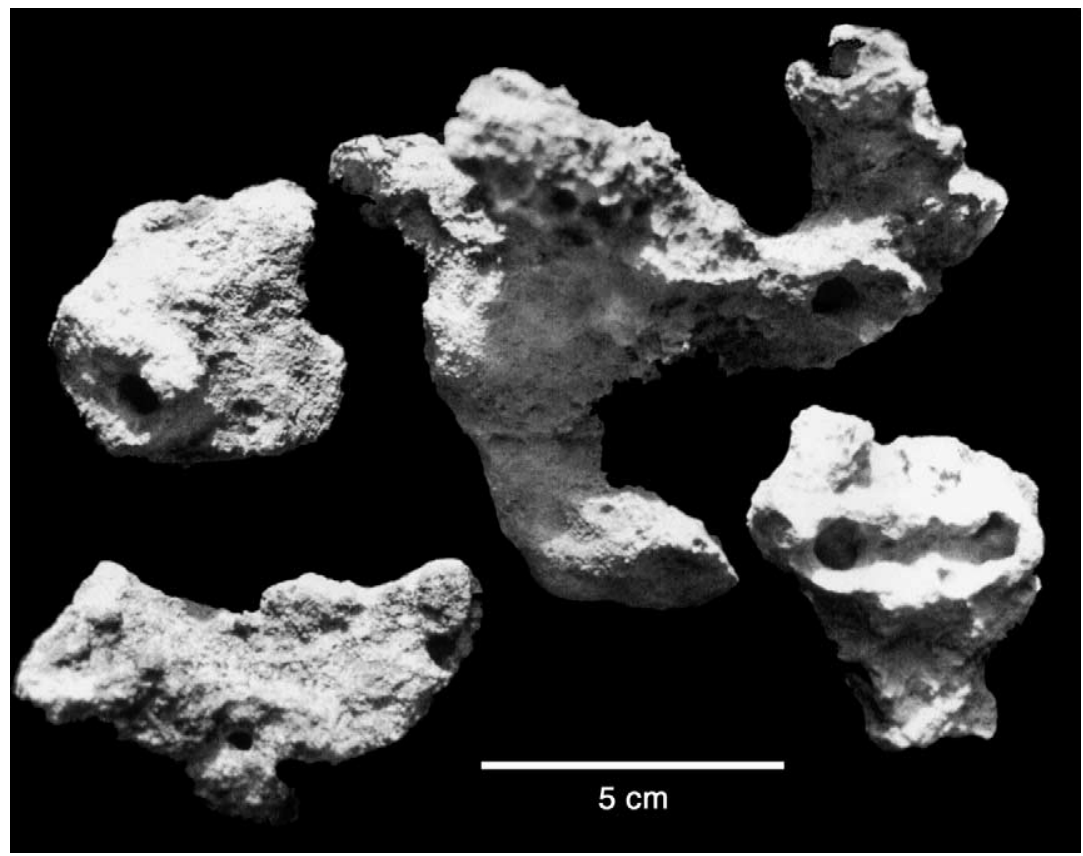

Fig. 10. Fragments of fossil Upogebia vasquezi burrows collected from the Grotto Beach Formation near Osprey Lake. Note the very thick, well-cemented burrow walls with smooth interior surfaces and the complexity of structure characteristic of this trace fossil.

from the basal part of the U-form; (2) burrow fragments with paired openings, mostly $2-4 \mathrm{~cm}$ apart; (3) other pairs $1-5 \mathrm{~cm}$ away from these openings; (4) burrow openings of $0.2-1 \mathrm{~cm}$ diameter; (5) segments with substantial burrow walls, $2-5 \mathrm{~cm}$ thick, some with evident nodose, irregularly pelleted exteriors; (6) burrow depths of as much as $11 \mathrm{~cm}$; and (7) preservation through cementation of fine-grained carbonate (sand and mud) sediment.

Fig. 11 presents views of a composite specimen where the shaft of a callianassid burrow has an in situ Upogebia vasquezi burrow preserved in very close proximity to it. Based on the Pigeon Creek findings, our interpretation is that this specimen represents fossilized burrowing at the uppermost surface of a coalesced callianassid mound. Now that these upogebiid trace fossils have been documented, we predict that future discoveries will occur with increasing frequency, and we suggest that such trace fossils likely are widespread in Quaternary lagoon-margin facies throughout the Bahamas and in other geologically similar areas. With collection of more and somewhat better preserved specimens, the establishment of a new ichnotaxon for these distinctive upogebiid trace fossils would seem to be warranted.

\section{Geological significance}

Facies representing deposition in sand-flat and lagoonal environments are widespread in the rock record of the Bahamas (Mitchell, 1987), including San Salvador (Hagey and Mylroie, 1995; Noble et al., 1995). Clearly bioturbation by callianassids is a major sedimentologic process in such environments, as shown by the Pigeon Creek example described herein and by the work of Tedesco and Wanless (1991) and others.

Bioturbation by the deep-tier callianassids would destroy burrows of the shallow tier under conditions of sand-flat and lagoonal sediment build-up that typically would occur with marine transgression. However, the shallow-tier burrows, particularly the thick-lined burrows of Upogebia 

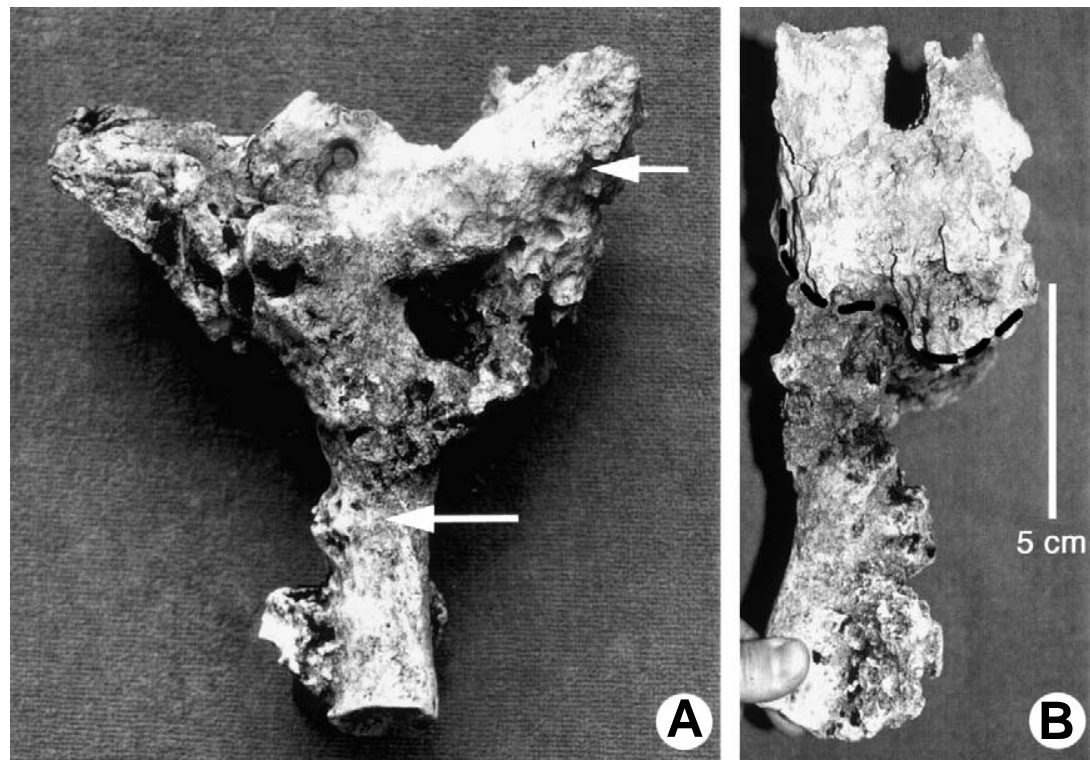

Fig. 11. Composite specimen of trace fossils collected in situ from an exposure surface of the Grotto Beach Formation near Osprey Lake. (A) Lower arrow marks the lithified fill of a callianassid burrow shaft (presumably formed by Glypturus acanthochirus) and upper arrow points to the outer surface of a near-complete Upogebia vasquezi burrow. (B) Same specimen as in A rotated $90^{\circ}$. Specimen is being held at base of the callianassid burrow shaft, with the $U$. vasquezi burrow at the top; basal extent of the $U$. vasquezi burrow is marked by the dashed line.

vasquezi, do have excellent potential for fossilization, particularly under conditions of sea-level stillstand and regression. The upogebiid trace fossils occur in late Pleistocene rocks of the Grotto Beach Formation and lie stratigraphically immediately below a terra rossa paleosol that formed during Wisconsinan time with a lowered eustatic sea level (Martin, 1999). On San Salvador, this paleosol marks the late Pleistocene-Holocene stratigraphic boundary (Carew and Mylroie, 1995). Based on the sediment characteristics, fossil molluscan fauna, and the upogebiid trace fossils, the sediments of this facies of the Grotto Beach Formation very probably were deposited on a sand flat similar to the modern flats at Pigeon Creek. Furthermore, given that U. vasquezi, the presumed maker of the Pleistocene trace fossils, requires the substrate stability of large intertidal callianassid mounds and thus had a narrow, intertidal range of occurrence, the trace fossils can be used as markers of former sea-level position, in this case at or very close to the last interglacial sea-level highstand. The occurrence of similar upogebiid trace fossils in other areas of the Bahamas and beyond has the potential to be highly useful in interpreting the sea-level history of the Quaternary tropical carbonate rocks containing them, as well as enabling more refined paleoenvironmental interpretations.

\section{Conclusions}

The burrowers and burrow interrelationships described herein for the tropical carbonate sand flats at Pigeon Creek on San Salvador Island, Bahamas are a prime marine example of organism ecosystem engineering and habitat modification or restructuring by the activities of trace-producing organisms. The deep burrows and prodigious burrowing activity of the callianassid Glypturus acanthochirus set the stage by creating a unique intertidal topography of large, coalesced mounds and ponded craters.

The surfaces of these large mounds are stabilized by microbial mats and colonized by the upogebiid Upogebia vasquezi and several species of fiddler crabs. Stabilized mound surfaces are vital 
to the life success of the shallow-tier burrowers, and the synecological relationship is one of dependence on the activity of Glypturus acanthochirus in the sense of neutral commensalism. The $U$. vasquezi burrows are complex, and their very thick walls and commonly criss-crossing, double Ustructure is unique among previously described upogebiid burrows. Much remains to be learned about the precise functions of these burrows, but their firm-walled construction grants them high potential for fossilization.

Fossil upogebiid burrows occur in lagoon-margin facies of the late Pleistocene Grotto Beach Formation on San Salvador Island, and they are common at some localities. These trace fossils are morphologically virtually identical to those made by modern Upogebia vasquezi on the Pigeon Creek sand flats. This represents the first described occurrence of upogebiid trace fossils in ancient tropical carbonate rocks. The trace fossils very likely were produced by $U$. vasquezi shrimp in an environmental setting analogous to that of the modern Pigeon Creek.

The upogebiid trace fossils are most abundant in beds lying directly below a terra rossa paleosol horizon that marks the late Pleistocene-Holocene stratigraphic boundary. This suggests that these beds represent an intertidal sand flat that formed during glacio-eustatic sea-level highstand, followed by regression associated with the onset of late Pleistocene glaciation. With their high preservation potential, these distinctive upogebiid trace fossils have real promise for use as both paleoenvironmental and sea-level position indicators throughout the Bahamas and in other geologically similar areas.

\section{Acknowledgements}

This paper is dedicated to the memory of the late Austin B. Williams of the U.S. National Marine Fisheries Service and Systematics Laboratory, National Museum of Natural History (Smithsonian Institution) who visited Pigeon Creek to work with the senior author and confirmed identifications of the decapod crustaceans discussed herein. We are indebted to the staff of the Gerace
Research Center (formerly the Bahamian Field Station) for full logistical support of our fieldwork on San Salvador Island. A number of students from Smith College, Emory University, and the Keck Geology Consortium Bahamas Project assisted with various aspects of the fieldwork, and we are grateful for their contributions. We thank William Miller III for convening the symposium on complex trace fossils held at the North American Paleontological Convention at the University of California, Berkeley in June 2001, where this paper was originally presented, and for serving with untiring efficiency and grace as the editor of this theme issue. Helpful critical reviews of an earlier version of this paper were made by $\mathrm{Ri}$ chard Bromley and Dirk Knaust. Smith College students Priscilla Delano and Emma Jugovich assisted with preparation of the figures. The senior author acknowledges the Committee on Faculty Compensation and Development at Smith College for partial support of fieldwork expenses associated with this research.

\section{References}

Allen, E.A., Curran, H.A., 1974. Biogenic sedimentary structures produced by crabs in lagoon margin and salt marsh environments near Beaufort, North Carolina. J. Sediment. Petrol. 44, 538-548.

Asgaard, U., Bromley, R.G., Hanken, N.-M., 1997. Recent firmground burrows produced by a upogebiid crustacean: palaeontological implications. Courier Forsch.-Inst. Senckenb. 201, 23-28.

Astall, C.M., Taylor, A.C., Atkinson, R.J.A., 1997. Behavioural and physiological implications of a burrow-dwelling lifestyle for two species of upogebiid mud-shrimp (Crustacea: Thalassinidea). Estuar. Coast. Shelf Sci. 44, 155-168.

Boardman, M.R., Neumann, A.C., Rasmussen, K.A., 1989. Holocene sea level in the Bahamas. In: Mylroie, J. (Ed.), Proceedings of the Fourth Symposium on the Geology of the Bahamas. Bahamian Field Station, San Salvador, pp. 45-52.

Bromley, R.G., 1996. Trace Fossils: Biology, Taphonomy and Applications, 2nd edn. Chapman and Hall, London, $361 \mathrm{pp}$.

Carew, J.L., Mylroie, J.E., 1995. Depositional model and stratigraphy for the Quaternary geology of the Bahama Islands. In: Curran, H.A., White, B. (Eds.), Terrestrial and Shallow Marine Geology of the Bahamas and Bermuda, Geol. Soc. Am. Spec. Pap. 300, 5-32.

Carney, C., Stoyka, G.S., Boardman, M.R., Kim, N., 1993. Depositional history and diagenesis of a Holocene strand 
plain, Sandy Hook, San Salvador, Bahamas. In: White, B. (Ed.), Proceedings of the Sixth Symposium on the Geology of the Bahamas. Bahamian Field Station, San Salvador, pp. 35-45.

Coelho, V.R., Cooper, R.A., Rodrigues, S.A., 2000. Burrow morphology and behavior of the mud shrimp Upogebia omissa (Decapoda: Thalassinidea: Upogebiidae). Mar. Ecol. Prog. Ser. 200, 229-240.

Crane, J., 1975. Fiddler Crabs of the World (Ocypodidae: genus $U c a$ ). Princeton University Press, Princeton, NJ, 736 pp.

Cummins, R.H., Boardman, M.R., Miller, A., 1995. Sedimentology and taphonomy of a Holocene carbonate lagoon, Pigeon Creek, San Salvador, Bahamas. In: Boardman, M. (Ed.), Proceedings of the Seventh Symposium on the Geology of the Bahamas. Bahamian Field Station, San Salvador, pp. $25-40$.

Curran, H.A., 1994. The palaeobiology of ichnocoenoses in Quaternary, Bahamian-style carbonate environments: The modern to fossil transition. In: Donovan, S.K. (Ed.), Palaeobiology of Trace Fossils. John Wiley and Sons, Chichester, UK, pp. 83-104.

Curran, H.A., (Ed.), 1997. Guide to Bahamian Ichnology: Pleistocene, Holocene, and Modern Environments. Bahamian Field Station, San Salvador, $61 \mathrm{pp}$.

Curran, H.A., White, B., 1991. Trace fossils of shallow subtidal to dunal ichnofacies in Bahamian Quaternary carbonates. Palaios 6, 498-510.

Curran, H.A., Williams, A.B., 1997. Ichnology of an intertidal carbonate sand flat: Pigeon Creek, San Salvador Island, Bahamas. In: Carew, J.L. (Ed.), Proceedings of the Eighth Symposium on the Geology of the Bahamas and Other Carbonate Regions. Bahamian Field Station, San Salvador, pp. 33-46.

Dworschak, P.C., Ott, J.A., 1993. Decapod burrows in mangrove-channel and back-reef environments at the Atlantic Barrier Reef, Belize. Ichnos 2, 277-290.

Godfrey, P.J., Edwards, D.C., Davis, R.L., Smith, R.R., Wells, J.A., 1994. Natural History of Northeastern San Salvador Island: A 'New World' Where the New World Began (Bahamian Field Station Trail Guide). Bahamian Field Station, San Salvador, 28 pp.

Griffis, R.B., Suchanek, T.H., 1991. A model of burrow architecture and trophic modes in thalassinidean shrimp (Decapoda: Thalassinidea). Mar. Ecol. Prog. Ser. 79, 171-183.

Hagey, F.M., Mylroie, J.E., 1995. Pleistocene lake and lagoon deposits, San Salvador Island, Bahamas. In: Curran, H.A., White, B. (Eds.), Terrestrial and Shallow Marine Geology of the Bahamas and Bermuda. Geol. Soc. Am. Spec. Pap. 300, 77-90.
Jones, C.G., Lawton, J.H., Shachak, M., 1994. Organisms as ecosystem engineers. Oikos 69, 373-386.

Kinoshita, K., 2002. Burrow structure of the mud shrimp Upogebia major (Decapoda: Thalassinidea: Upogebiidae). J. Crustac. Biol. 22, 474-480.

Martin, A.J., 1999. Fossil upogebiid burrows and their geologic significance: Grotto Beach Formation (Pleistocene), San Salvador, Bahamas. In: Curran, H.A., Mylroie, J.E. (Eds.), Proceedings of the Ninth Symposium on the Geology of the Bahamas and Other Carbonate Regions. Bahamian Field Station, San Salvador, pp. 81-92.

Miller, W., III, 1998. Complex marine trace fossils. Lethaia 31, $29-32$.

Miller, W., III, 2002. Complex trace fossils as extended organisms: a proposal. N. Jb. Geol. Paläontol. Mh. 2002, 147158 .

Mitchell, S.W., 1987. Sedimentology of Pigeon Creek, San Salvador Island, Bahamas. In: Curran, H.A. (Ed.), Proceedings of the Third Symposium on the Geology of the Bahamas. Bahamian Field Station, Ft. Lauderdale, FL, pp. 215230.

Nickell, L.A., Atkinson, R.J.A., 1995. Functional morphology of burrows and trophic modes of three thalassinidean shrimp species, and a new approach to the classification of thalassinidean burrow morphology. Mar. Ecol. Prog. Ser. 128, 181-197.

Noble, R.S., Curran, H.A., Wilson, M.A., 1995. Paleoenvironmental and paleoecologic analyses of a Pleistocene molluscrich lagoonal facies, San Salvador Island, Bahamas. In: Curran, H.A., White, B. (Eds.), Terrestrial and Shallow Marine Geology of the Bahamas and Bermuda. Geol. Soc. Am. Spec. Pap. 300, 91-103.

Shinn, E.A., 1968. Burrowing in Recent lime sediments of Florida and the Bahamas. J. Paleontol. 42, 879-894.

Tedesco, L.P., Wanless, H.R., 1991. Generation of sedimentary fabrics and facies by repetitive excavation and storm infilling of burrow networks, Holocene of South Florida and Caicos Platform, B.W.I. Palaios 6, 326-343.

Thompson, R.K., Pritchard, A.W., 1969. Respiratory adaptations of two burrowing crustaceans, Callianassa californiensis and Upogebia pugettensis (Decapoda, Thalassinidea). Biol. Bull. Mar. Biol. Lab. Woods Hole 136, 274-287.

Tudhope, A.W., Scoffin, T.P., 1984. The effects of Callianassa bioturbation on the preservation of carbonate grains in $\mathrm{Da}$ vies Reef Lagoon, Great Barrier Reef, Australia. J. Sediment. Petrol. 54, 1091-1096.

Williams, A.B., 1993. Mud Shrimps, Upogebiidae, from the Western Atlantic (Crustacea: Decapoda: Thalassinidea). Smithsonian Contrib. Zool. 544, 77 pp. 